\title{
Investigation of the Impact of Active Layer and Charge Transfer Layer Materials on the Performance of Polymer Solar Cells through Simulation
}

\author{
Fekadu Gochole Aga ${ }^{D},{ }^{1}$ Fetene Fufa Bakare ${ }^{D},{ }^{1}$ Solomon Tiruneh Dibaba ${ }^{D},{ }^{2}$ \\ Demissie Jobir Gelmecha $\mathbb{( D}^{3},{ }^{3}$ and Chernet Amente $\mathbb{1}^{4}$ \\ ${ }^{1}$ Department of Materials Science and Engineering, School of Mechanical, Chemical and Materials Engineering, \\ Adama Science and Technology University, Adama, P.O. Box 1888, Ethiopia \\ ${ }^{2}$ Department of Applied Physics, School of Applied Natural Science, Adama Science and Technology University, Adama, \\ P.O. Box 1888, Ethiopia \\ ${ }^{3}$ Department of Electronics and Communication Engineering, School of Electrical Engineering \& Computing, \\ Adama Science and Technology University, Adama, P.O. Box 1888, Ethiopia \\ ${ }^{4}$ Departmet of Physics, College of Computational and Natural Science, Addis Ababa University, Addis Ababa, \\ P.O. Box 1176, Ethiopia
}

Correspondence should be addressed to Fekadu Gochole Aga; fekadu.gochole@astu.edu.et

Received 4 November 2021; Accepted 4 February 2022; Published 27 February 2022

Academic Editor: Claudio Pettinari

Copyright (C) 2022 Fekadu Gochole Aga et al. This is an open access article distributed under the Creative Commons Attribution License, which permits unrestricted use, distribution, and reproduction in any medium, provided the original work is properly cited.

\begin{abstract}
This article reports polymer solar cell performance evaluated using general-purpose photovoltaic device model (GPVDM) software for various device structures. The essential parameters of the cell such as short circuit current density (JSC), open-circuit voltage (VOC), fill factor (FF), and power conversion efficiency (PCE) are evaluated for these structures. The simulation result shows the performance of the cells could be highly affected by both interfacial and active layers. Among the demonstrated device structures, better performance is observed for device structure ITO/V2O5/PTB7: PC70BM/TiOx/Al with $10.4 \mathrm{~mA} / \mathrm{cm}^{2}$ short circuit current density, $0.89 \mathrm{~V}$ open-circuit voltage, $59.5 \%$ fill factor, and $6.1 \%$ power conversion efficiency. The study is useful for a better understanding of the powerful effect of the materials in the device structure on the performance of the cell and thereby determines the proper device structure and materials for improving the performance of the cell.
\end{abstract}

\section{Introduction}

Nowadays, the serious problems observed in the world are global warming and the enhanced greenhouse effect as the result of fossil fuel-based energy consumption $[1,2]$. The solar energy that is sustainable and inexhaustible is one of the renewable sources of energy converted sunlight into electrical energy using solar cell devices which are dubbed as the best solution for the aforementioned problems. The conversion of solar radiation into electricity using solar cells has no pollutants, and the energy obtained is proportional to the quantity of absorbed solar radiations $[3,4]$. Based on the materials used to fabricate the cell, there are various kinds of solar cells; however, the challenges facing solar cells are efficiency, lifetime, cost, and the availability of the materials for fabrication [5-9]. Among various kinds of solar cells, polymer-based organic solar cells have many interesting features and research progress on polymer solar cells, and polymer-based organic solar cells are a promising renewable source of energy for the coming generation [10-13]. The techniques, low fabrication cost, flexibility, and portability make polymer solar cells advantageous over silicon-based solar cells [14-17]. The power conversation efficiency of nonfullerene acceptor-based polymer solar 


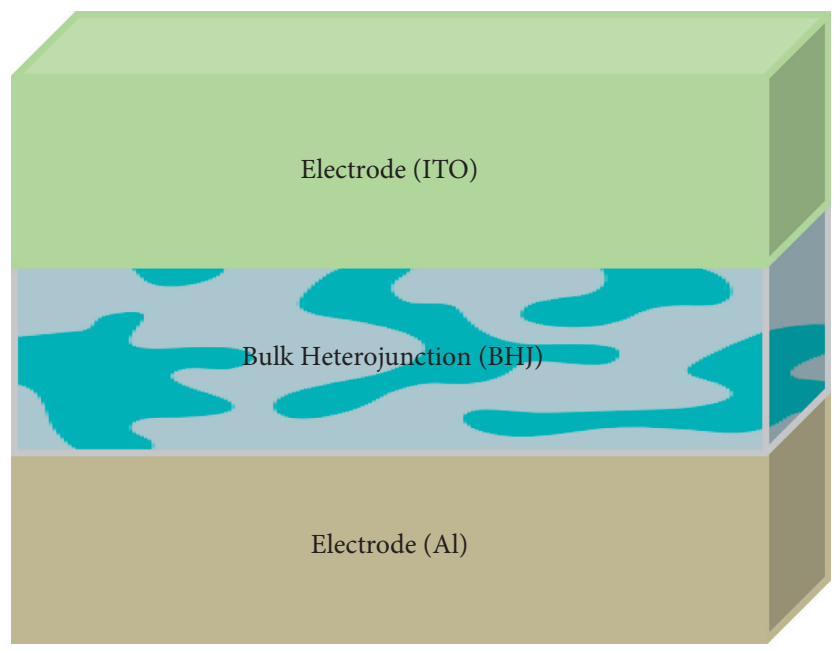

FIgURE 1: The basic device structure of polymer solar cells.

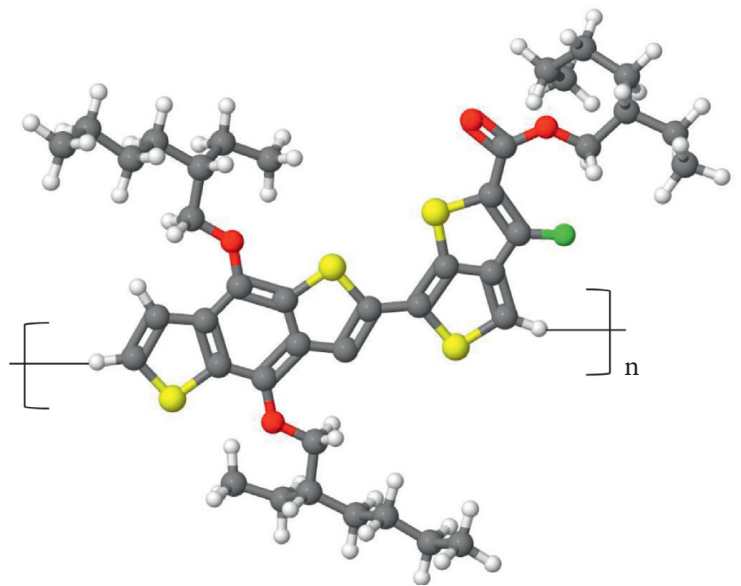

(a)

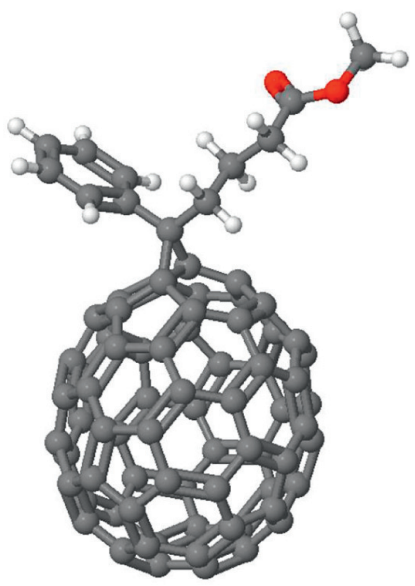

(b)

FIgURE 2: Molecular structure of PTB7 (a) and PC70BM (b) (colors: white represents hydrogen, red represents oxygen, yellow represents sulfur, green represents fluorine, and dark grey represents carbon).

cells is maintained over $16 \%$ through various techniques [18-20]; however, fullerene-based polymer solar cells are still low with respect to nonfullerene. This work focuses on the method of optimizing the performance of the bulk heterojunction conjugated polymer and electron acceptor fullerene-based polymer solar cells that can be easily synthesized by a simple process based on device structure using materials-based laboratory general-purpose photovoltaic device model (GPVDM) software. GPVDM is the freely available software designed to simulate optoelectronics devices, such as OPV, OLED, and OFTE [21].

The basic device structure of polymer solar cells comprises indium tin oxide (ITO) coated glass used as a front electrode which is considered as an anode, light-absorbing layer, and back electrode for photon-created electrons collector which acts as a cathode [22] as shown in Figure 1. Few experimental investigations of the cell performance based on device structure have been carried out; however, the detailed analysis of device architecture impact on the cell performance is still an infant and not yet evaluated using GPVDM software. The most important light-absorbing layer was a blend of the donor and acceptor organic materials that play a vital role in the creation of excitons (electron-hole pairs) and is also used to reduce the recombination of electron-hole that minimize the performance of the cell $[23,24]$. In addition to the active layer, the electron and hole transport layers between the active layer and electrode are used to reduce the recombination of the free charge carriers and also prevent the interpenetration of the active layer into the electrode during device fabrication [25]. Thus, an appropriate selection of materials for device structure is very important to optimize cell performance.

In this study, we investigate the impact of device architecture on the performance of the cell for different structures. In the simulation, the various light-absorbing materials along with different thin films as hole and electron transport layers are conducted in order to optimize the performance of the cell. Figures 2(a) and 2(b) show the 
TABLE 1: Electrical parameters used for simulation [26-28].

\begin{tabular}{lc}
\hline Parameters & Value \\
\hline Band gap of P3HT $(\mathrm{eV})$ & 1.9 \\
Band gap of PTB7 $(\mathrm{eV})$ & 1.84 \\
Band gap of PCBM $(\mathrm{eV})$ & 2.4 \\
Band gap of PC70BM $(\mathrm{eV})$ & 1.8 \\
Electron mobility $\left(\mathrm{cm}^{2} / \mathrm{V} . \mathrm{s}\right)$ & $1.0 \times 10^{-3}$ \\
Hole mobility $\left(\mathrm{cm}^{2} / \mathrm{V} . \mathrm{s}\right)$ & $2.0 \times 10^{-4}$ \\
Donor concentration $\left(\mathrm{m}^{-3}\right)$ & $2.8 \times 10^{27}$ \\
Acceptor concentration $\left(\mathrm{m}^{-3}\right)$ & $2.8 \times 10^{25}$ \\
\hline
\end{tabular}

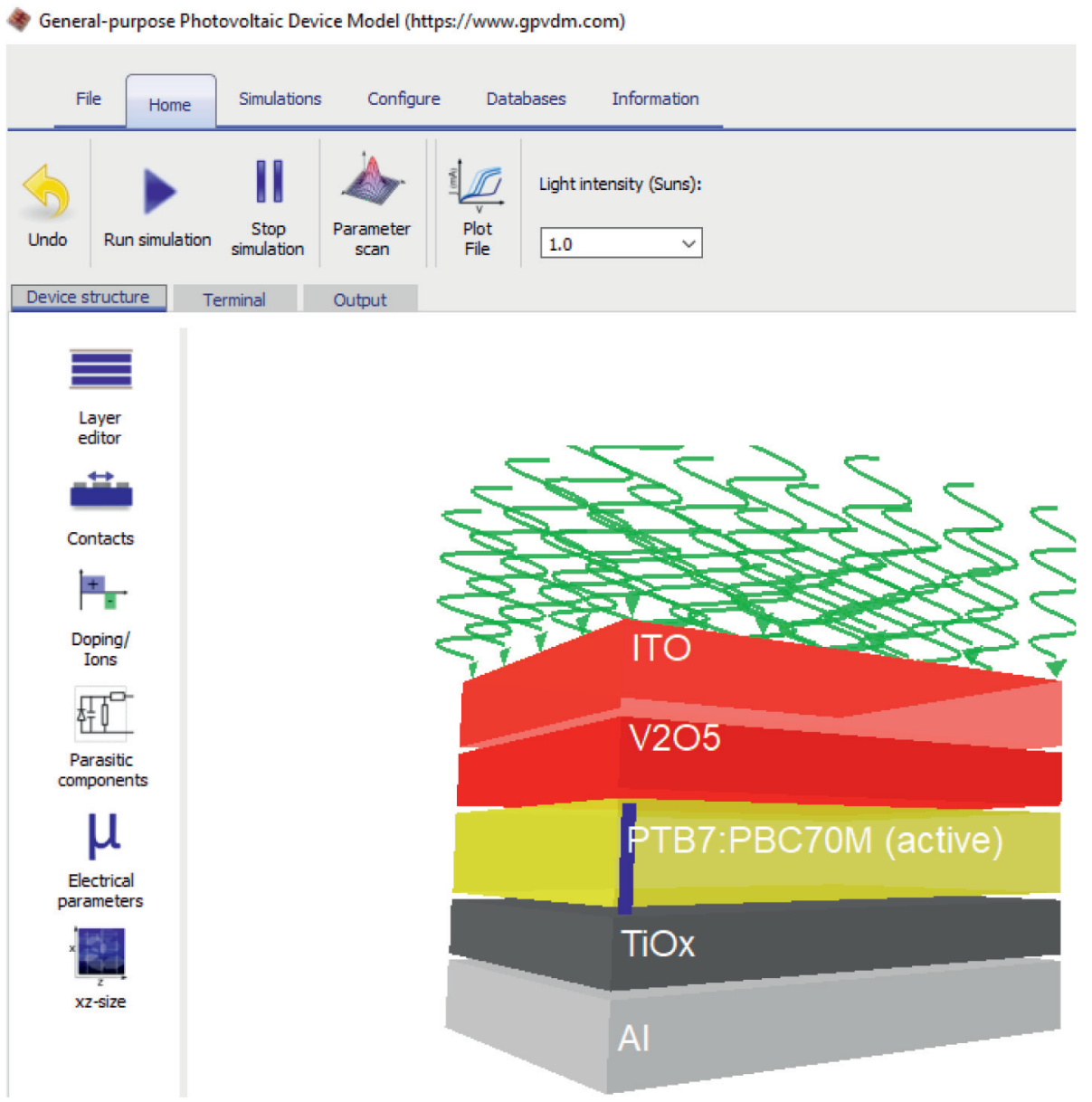

FIGURE 3: Electrical simulation window for the architecture of the studied solar cell.

molecular structures of PTB7 and PC70BM, respectively, that give better performance among used active layers blend, and the list of parameters used for simulation purposes are given in Table 1.

\section{Result and Discussion}

The exciton generation by a photon in a blend of donor and acceptor and subsequent separation of exciton into electron and hole to generate power are discussed in detail. Two blends of donor and acceptor along with various electron and hole transport layers at different thicknesses were used to investigate the performance of the cells with the help of GPVDM software that consists of full information of the electrical and optical properties of the materials used in the device structure. GPVDM software for solar cell simulation describes electron and hole transport based on bipolar drift diffusion in 1D as that can be given by equations (1) and (2) [29]. Figure 3 illustrates the electrical simulation window of GPVDM used to analyze the cell performance.

$$
\begin{aligned}
& J_{n}=q \mu_{e} n \frac{\partial E_{\mathrm{LUMO}}}{\partial x}+q D_{n} \frac{\partial n}{\partial x}, \\
& J_{p}=q \mu_{p} p \frac{\partial E_{\mathrm{HOMO}}}{\partial x}-q \mu_{p} \frac{\partial p}{\partial x} .
\end{aligned}
$$

Through the simulation work, dependencies of device performance on the structure were clarified by changing 


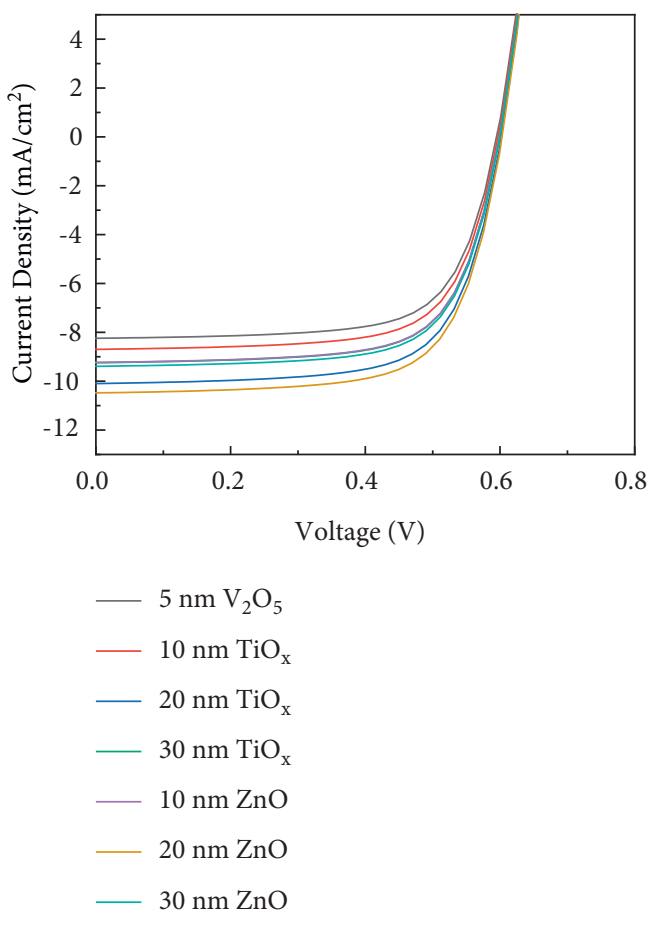

(a)

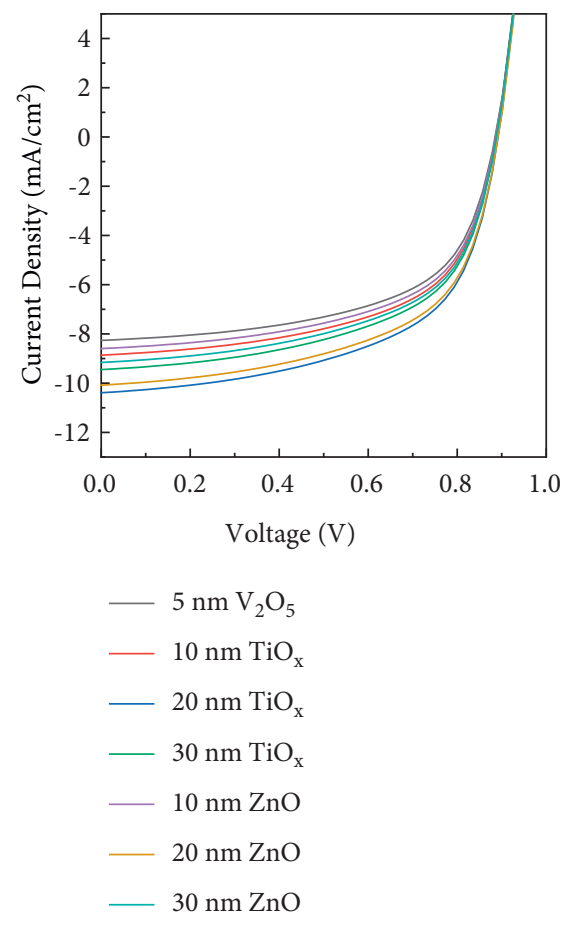

(b)

FIGUre 4: Current density vs. voltage for (a) P3HT: PCBM and (b) PTB7 : PC70BM active layers with different interfaces used as hole and electron transfer layer with various thicknesses.

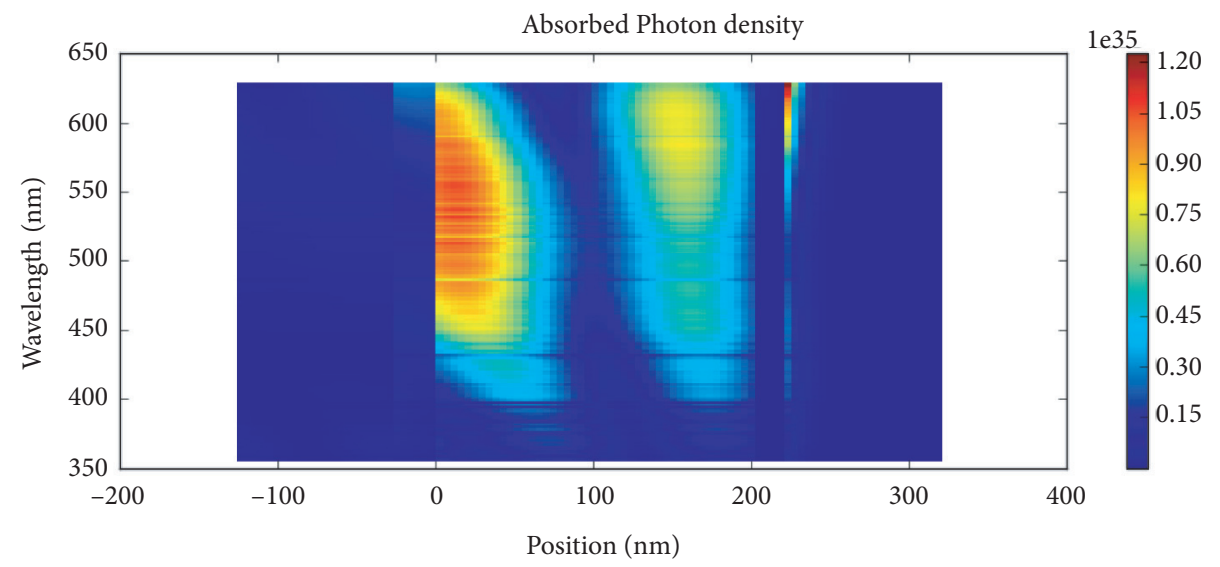

FIgUre 5: Absorbed photon density in different components of the device architecture of ITO/V2O5/PTB7: PC70BM/TiOx/Al.

TABLE 2: Evaluated parameters of the cells for various active and interface layers.

\begin{tabular}{lccccc}
\hline Active layer & Thickness of interface layer & JSC $\left(\mathrm{mA} / \mathrm{cm}^{2}\right)$ & VOC $(\mathrm{V})$ & FF $(\%)$ & PCE $(\%)$ \\
\hline \multirow{2}{*}{ PTB7 : PC70BM } & $\mathrm{TiOx} / 20 \mathrm{~nm}$ & 10.4 & 0.89 & 59.5 & 6.1 \\
& $\mathrm{ZnO} / 20 \mathrm{~nm}$ & 10.2 & 10.1 & 0.89 & 57.7 \\
\hline P3HT: PCBM & $\mathrm{TiOx} / 20 \mathrm{~nm}$ & 10.4 & 0.601 & 68.9 & 4.6 \\
& $\mathrm{ZnO} / 40 \mathrm{~nm}$ & & 68.8 & 4.7 \\
\hline
\end{tabular}

donor/acceptor materials and electron transfer layers at different thicknesses. The comparison of the simulation results for different configurations demonstrated that the architecture of the device is critically important to achieving performance improvement of the cell. For those various active and different interface layers, the current density versus voltage is shown in Figure 4. Figure 4(a) shows the current density versus voltage for the active layer of P3HT: PCBM and Figure 4(b) for the active layer of PTB7: PC70BM. We also investigate the performance of the cells 


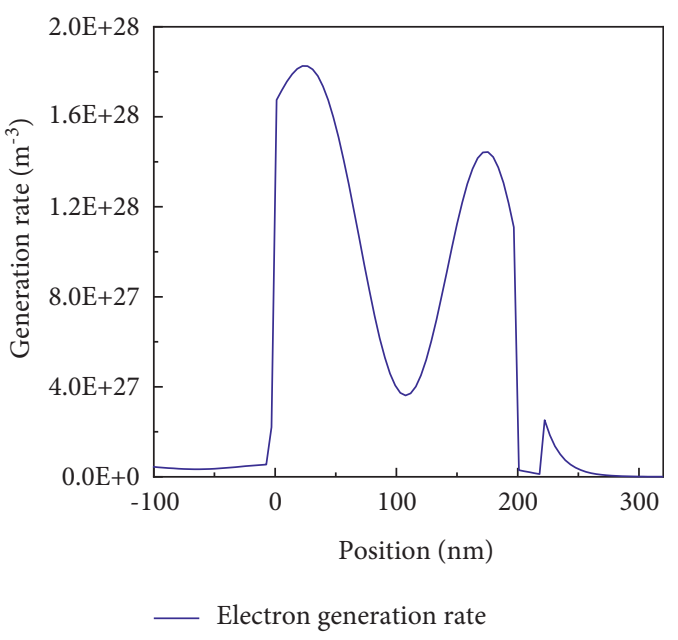

(a)

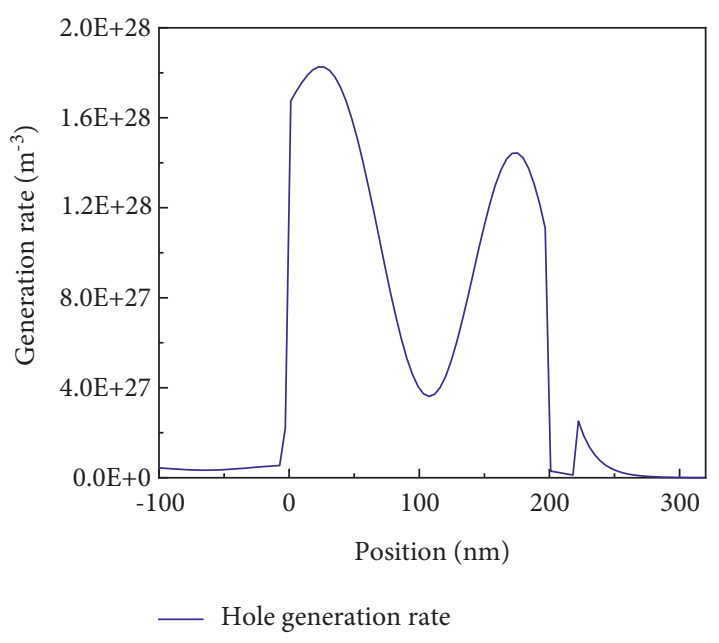

(b)

FIgURE 6: Generation rate of (a) electron and (b) hole for ITO/V2O5/PTB7: PC70BM/TiOx/Al device architecture.

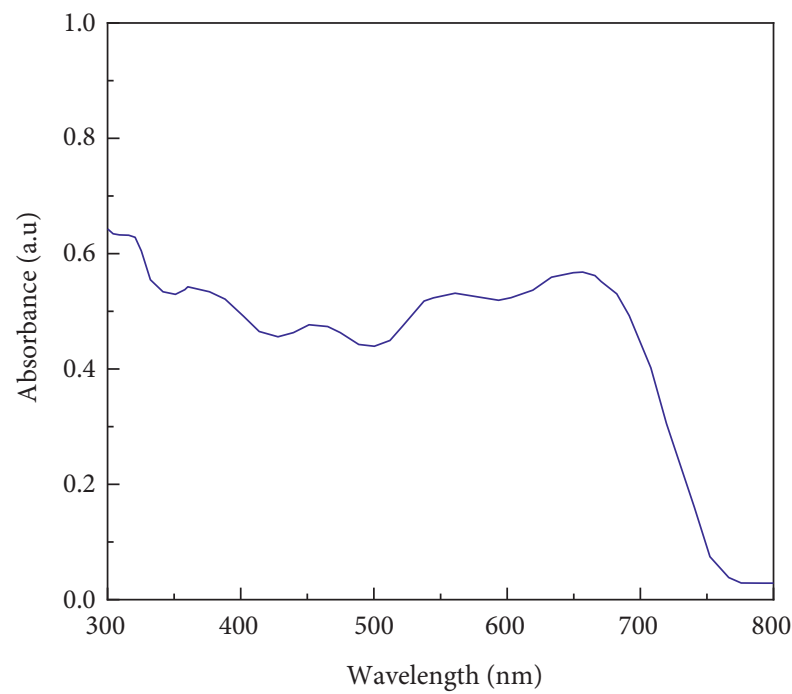

(a)

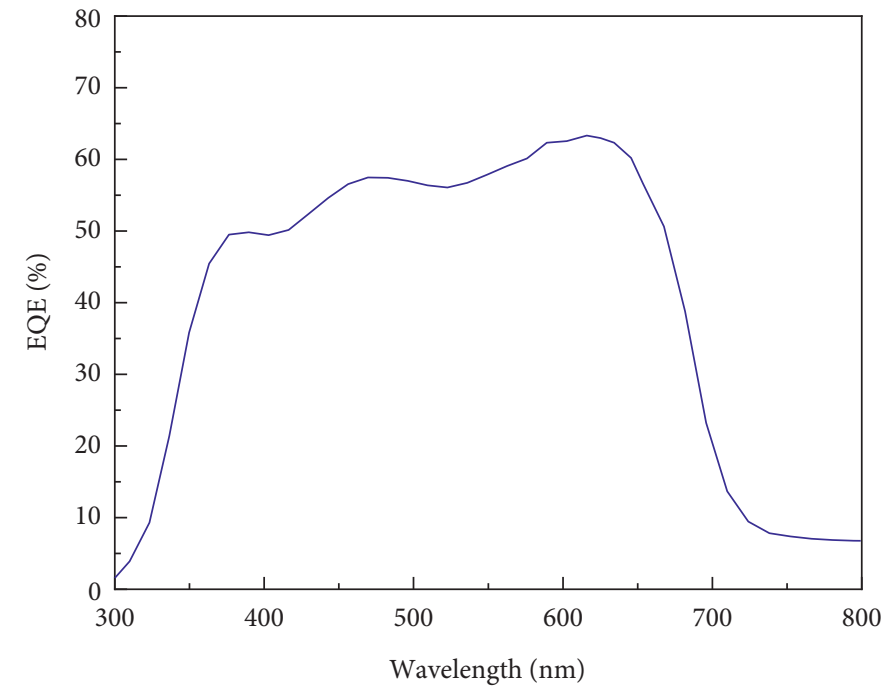

(b)

Figure 7: (a) Absorbance of PTB7: PC70BM and (b) EQE spectra of ITO/V2O5/PTB7 : PC70BM/TiOx/Al.

for $\mathrm{TiOx}$ and $\mathrm{ZnO}$ as electron transfer layers at the same thickness. The comparison of the simulation results demonstrated that the cell with structure ITO/V2O5/PTB7: $\mathrm{PC} 70 \mathrm{BM} / \mathrm{TiOx} / \mathrm{Al}$ with $20 \mathrm{~nm} \mathrm{TiOx}$ as electron transfer layer together with $5 \mathrm{~nm}$ vanadium pentoxide (V2O5) hole transfer layer shows better performance according to our investigation. As shown in the simulation results, the thickness and materials used for the interface layers also play a major role in cell performance. This is due to the ohmic contact of low work function metal oxide with electron acceptor that makes low series resistance, selectively transfers electron, and improves parallel resistance [30]. For all device structures, the current density $(\mathrm{J})$ versus voltage $(\mathrm{V})$ is evaluated under solar irradiance of $100 \mathrm{~mW} / \mathrm{cm}^{2}$ at constant room temperature.

Figure 5 illustrates the photon absorber density in each component of the device structure ITO/V2O5/PTB7:
PC70BM/TiOx/Al that indicates the wide absorption spectrum edges which match in the range of visible photon wavelength spectrum. As indicated in the figure, the high photon absorbed density observed in the active layer could play enhancing role in the creation of more excitons to optimize the performance of the cell.

The evaluated short circuit current density (JSC), opencircuit voltage (VOC), fill factor (FF), and power conversion efficiency (PCE) of the various cell structures are given in Table 2. Better performances are obtained for $20 \mathrm{~nm}$ TiOx thick electron transfer layer for the device structure ITO/ V2O5/PTB7: PC70BM/TiOx/Al with $10 \mathrm{~mA} / \mathrm{cm}^{2}$ short circuit current density, $0.89 \mathrm{~V}$ open-circuit voltage, $59.5 \%$ fill factor, and $6.1 \%$ power conversion efficiency. As a result of photon absorption by the active layer, excitons are created with sequential charge carrier separation into hole and electron at the interface of donor and acceptor. Electron and 
hole generation rate as the position of device components have been demonstrated and shown in Figures 6(a) and 6(b), respectively. Accordingly, both charge carriers' generation rates are high in the bulk heterojunction blend of donor and acceptor. Thus, the bulk heterojunction used as an active layer plays a major role in polymer solar cell efficiency optimization.

The absorbance of PTB7: PC70BM and external quantum efficiency (EQE) of the device structure of ITO/V2O5/ PTB7 : PC70BM/TiOx/Al were demonstrated and are shown in Figures $7(\mathrm{a})$ and $7(\mathrm{~b})$, respectively. As shown in Figure $7(a)$, the device shows better absorption in visible spectra, and in Figure 7(b), EQE follows the absorption in the visible spectrum and shows opposite to the absorption in UV $[27,31]$.

\section{Conclusion}

The work widely shows the importance of device structure to optimize the performance of polymer solar cells and helps to understand the challenge in developing the active layer and the interfacial influence on the cell performance optimization. The simulation result with $5 \mathrm{~nm}$ V2O5 thickness as hole transport layer and $20 \mathrm{~nm} \mathrm{TiOx}$ as electron transport layer with ITO/V2O5/PTB7 : PC70BM/TiOx/Al device structure shows $10.4 \mathrm{~mA} / \mathrm{cm}^{2}$ short circuit current density, $0.89 \mathrm{~V}$ open-circuit voltage, $59.5 \%$ fill factor, and $6.1 \%$ power conversion efficiency. The study gives guidance for a better understanding of the powerful impact of the structure of materials on the performance of the cell and helps to find the solution in the progress of improving the efficiency of polymer solar cells.

\section{Data Availability}

The data used to support the findings of this study are included in the article.

\section{Conflicts of Interest}

The authors declare that they have no conflicts of interest.

\section{References}

[1] V. Masson, M. Bonhomme, J.-L. Salagnac, X. Briottet, and A. Lemonsu, "Solar panels reduce both global warming and urban heat island," Frontiers in Environmental Science, vol. 2, no. 14, pp. 1-9, 2014.

[2] M. Gul, Y. Kotak, and T. Muneer, "Review on recent trend of solar photovoltaic technology," Energy Exploration \& Exploitation, vol. 34, no. 4, pp. 485-526, 2016.

[3] T. Tsoutsos, N. Frantzeskaki, and V. Gekas, "Environmental impacts from the solar energy technologies," Energy Policy, vol. 33, pp. 89-296, 2005.

[4] A. A. F. Husain, W. Z. W. Hasan, S. shafie, M. N. Hamidon, and S. S. Pandey, "A review of transparent solar photovoltaic technologies," Renewable and Sustainable Energy Reviews, vol. 94, pp. 779-791, 2018.

[5] H.-Y. Chen, J. Hou, S. Zhang et al., "Polymer solar cells with enhanced open-circuit voltage and efficiency," Nature Photonics, vol. 3, no. 11, pp. 649-653, 2009.
[6] Z. Hu, J. Zhang, Z. Hao, and Y. Zhao, "Influence of doped PEDOT:PSS on the performance of polymer solar cells," Solar Energy Materials and Solar Cells, vol. 95, no. 10, pp. 2763-2767, 2011.

[7] A. H. H. Ali, H. A. S. Zeid, and H. M. G. Alfadhli, "Energy performance, environmental impact, and cost assessments of a photovoltaic plant under Kuwait climate condition," Sustainable Energy Technologies and Assessments, vol. 22, pp. 25-33, 2017.

[8] X. Fu, L. Xu, J. Li, X. Sun, and H. Peng, "Flexible solar cells based on carbon nanomaterials," Carbon, vol. 139, pp. 1063-1073, 2018.

[9] J. A. Luceno-Sanchez, A. M. Diez-Pascual, and R. P. Capilla, "Materials for photovoltaic: state of art and recent developments," International Journal of Molecular Sciences, vol. 20, pp. 1-42, 2019.

[10] M. Kaltenbrunner, M. S. White, E. D. Głowacki et al., "Ultrathin and lightweight organic Solar cells with high flexibility," Nature Communications, vol. 3, no. 770, pp. 1-7, 2012.

[11] G. Li, R. Zhu, and Y. Yang, "Polymer solar cells," Nature Photonics, vol. 6, no. 3, pp. 153-161, 2012.

[12] A. E. Ostfeld and A. C. Arias, "Flexible Photovoltaic power systems: integration opportunities, challenges and advances," Flex. Print. Electron, vol. 2, no. 1, pp. 1-24, 2017.

[13] I. Borazan, Y. Altin, A. Demir, and A. Celik Bedeloglu, "Characterization of organic solar cells using semiconducting polymers with different bandgaps," Journal of Polymer Engineering, vol. 39, no. 7, pp. 636-641, 2019.

[14] Z. Wang, C. Zhang, D. Chen et al., "ITO-free semitransparent organic solar cells based on silver thin film electrodes," International Journal of Photoenergy, vol. 2014, Article ID 209206, 7 pages, 2014.

[15] Y. Li, H. Yu, X. Huang, Z. Wu, and M. Chen, "A simple synthesis method to prepare a molybdenum oxide holetransporting layer for efficient polymer solar cells," RSC Advances, vol. 7, no. 13, pp. 7890-7900, 2017.

[16] S.-Y. Chang, P. Cheng, G. Li, and Y. yang, "Transparent polymer photovoltaics for solar energy harvesting and beyond," Joule, vol. 2, no. 6, pp. 1039-1054, 2018.

[17] M. Erray, M. Hanine, E.-M. Boufounas, and A. El Amrani, "Combined effects of carriers charge mobility and electrodes work function on the performances of polymer/fullerene P3HT:PCBM based organic photovoltaic solar cell," The European Physical Journal - Applied Physics, vol. 82, no. 3, Article ID 30201, 2018.

[18] W. Xu, X. Ma, J. H. Son et al., "Smart ternary strategy in promoting the performance of polymer solar cells based on bulck-heterojunction or layer-by-layer structure," Nano-Micro Small, vol. 18, no. 4, Article ID 2104215, 2021.

[19] X. Wang, Q. Sun, J. Gao et al., "Recent progress of organic photovoltaics with efficiency over 17\%," Energies, vol. 14, no. 14, pp. 1-27, 2021.

[20] C. Xu, K. Jin, Z. Xiao et al., "Wind bandgap polymer with narrow photon harvesting in visible light range enable efficient semitransparent organic photovoltaics," Advanced Functional Materials, vol. 32, no. 52, pp. 1-8, 2021.

[21] N. Singh, A. Chaudhary, S. Saxena, M. Saxena, and N. Rastogi, "Electrical simulation of organic solar cell at different charge carries mobility," IOSR Journal of Applied Physics, vol. 9, no. 2, pp. 1-4, 2017.

[22] L. Hu, J. Song, X. Yin, Z. Su, and Z. Li, "Research progress on polymer solar cell based on PEDOT: PSS electrodes," Polymer, vol. 12, pp. 1-19, 2020. 
[23] A. J. Moulé, J. B. Bonekamp, and K. Meerholz, "The effect of active layer thickness and composition on the performance of bulk-heterojunction solar cells," Journal of Applied Physics, vol. 100, no. 9, pp. 1-7, Article ID 094503, 2006.

[24] K. Weng, L. Ye, L. Zhu et al., "Optimized active layer morphology toward efficient and polymer batch insensitive organic solar cells," Nature Communications, vol. 11, pp. 2855-2859, 2020.

[25] Z. Yin, J. Wei, and Q. Zheng, "Interfacial materials for organic solar cells: recent advance and perspectives," Advanced Science, vol. 3, pp. 1-37, 2016.

[26] C. T. Howells, K. Marbou, H. Kim et al., "Enhanced organic solar cells efficiency through electronic and electro-optic effects resulting from charge transfers in polymer hole transport blends," Journal of Materials Chemistry, vol. 4, no. 1, pp. 4252-4263, 2016.

[27] B. Ebenhoch, S. A. J. Thomson, K. Genevičius, G. Juška, and I. D. W. Samuel, "Charge carrier mobility of the organic photovoltaic materials PTB7 and PC71BM and its influence on device performance," Organic Electronics, vol. 22, pp. 62-68, 2015.

[28] P. Sinha and R. Baghel, "Effect of series resistance and layer thickness on PCE and fill factor in organic solar cell with P3HT: PCBM active layer," International research journal of engineering and technology, vol. 6, no. 12, pp. 1571-1574, 2019.

[29] N. Rastogi, N. Singh, and S. Saxena, "Analysis of organic photovoltaic device at different series resistances," Universal journal of Materials Science, vol. 5, no. 4, pp. 83-87, 2017.

[30] A. Hayakawa, O. Yoshikawa, T. Fujieda, K. Uehara, and S. Yoshikawa, "High performance polythiophene/fullerene bulk-heterojunction solar cell with a TiOx hole blocking layer," Applied Physics Letters, vol. 90, no. 16, Article ID 163517, 2007.

[31] I. Etxebarria, A. Guerrero, J. Albero, G. Garcia-Belmonte, E. Palomares, and R. Pacios, "Inverted vs. standard PTB7: PC70BM organic photovoltaic devices. The benefit of highly selective and extracting contacts in device performance," Organic Electronics, vol. 15, no. 11, pp. 2756-2762, 2014. 